\title{
Gene Expression and Distribution of Key Bone Turnover Markers in the Callus of Estrogen-Deficient, Vitamin D-Depleted Rats
}

\author{
Gunhild Melhus • S. H. Brorson • E. S. Baekkevold • \\ G. Andersson • R. Jemtland • O. K. Olstad • \\ F. P. Reinholt
}

Received: 25 September 2009/ Accepted: 24 April 2010/Published online: 22 May 2010

(C) The Author(s) 2010. This article is published with open access at Springerlink.com

\begin{abstract}
An experimental rat model was used to test the hypothesis that in osteoporosis (OP) the molecular composition of the extracellular matrix in the fracture callus is disturbed. OP was induced at 10 weeks of age by ovariectomy and a vitamin $\mathrm{D}_{3}$-deficient diet, and sham-operated animals fed normal diet served as controls. Three months later a closed tibial fracture was made and stabilized with an intramedullary nail. After 3 and 6 weeks of healing, the animals were killed and the fracture calluses examined
\end{abstract}

Electronic supplementary material The online version of this article (doi:10.1007/s00223-010-9371-2) contains supplementary material, which is available to authorized users.

The authors have stated that they have no conflict of interest.

G. Melhus · S. H. Brorson · E. S. Baekkevold · F. P. Reinholt Institute of Pathology, University of Oslo, Oslo, Norway

G. Melhus - S. H. Brorson - E. S. Baekkevold · F. P. Reinholt Department of Pathology, Oslo University Hospital, Rikshospitalet, 0027 Oslo, Norway

R. Jemtland

Endocrine Section, Department of Medicine, Oslo University

Hospital, Rikshospitalet, Oslo, Norway

G. Andersson

Department of Laboratory Medicine, Division of Pathology, F46,

Karolinska Institutet, Karolinska University Hospital Huddinge,

14186 Huddinge, Sweden

O. K. Olstad

Department of Clinical Chemistry, Oslo University Hospital,

Ullevaal, Oslo, Norway

G. Melhus $(\square)$

A3.M006, Institute of Pathology, Oslo University Hospital,

Rikshospitalet, Sognsvannsveien 20, 0027 Oslo, Norway

e-mail: gunhild.melhus@rr-research.no with global gene expression, in situ mRNA expression, and ultrastructural protein distribution of four bone turnover markers: osteopontin, bone sialoprotein, tartrate-resistant acid phosphatase, and cathepsin K. Global gene expression showed a relatively small number of differently regulated genes, mostly upregulated and at 3 weeks. The four chosen markers were not differently regulated, and only minor differences in the in situ mRNA expression and ultrastructural protein distribution were detected. Gene expression and composition of fracture calluses are not generally disturbed in experimental OP.

Keywords Fracture healing - Osteoporosis .

Global gene expression - Noncollagenous matrix protein

Osteoporosis (OP) is a multifactorial metabolic bone disease characterized by reduced bone density and quality, resulting in loss of mechanical strength and increased susceptibility to fracture. Women undergo a rapid phase of bone loss starting 2-3 years before ovarian failure, remaining up to 5 years after menopause, and in many cases with postmenopausal OP as the final outcome $[1,2]$. However, whether and to what extent this disrupted balance between bone formation and bone resorption [3, 4] influences healing of fractures in OP individuals remain to be answered.

Fracture healing is a complex process that takes place in order to fully restore anatomic and functional structure following injury, involving cell proliferation and differentiation, chemotaxis, and synthesis of extracellular matrix (ECM). Although delayed healing of femoral neck fractures in OP patients has been reported [5], no studies reporting impaired healing in OP compared to healthy agematched controls have been published. Due to ethical concerns and multiple confounding factors, most studies 
have been performed in animal models. The ovariectomized (OVX) rat model has been approved by the FDA [6] as a relevant model for the study of postmenopausal OP, mimicking postmenopausal trabecular bone loss when examined over relatively short periods of time. Impaired fracture healing has been reported in this model in early [7] and late [8] stages, as evaluated by radiographic, histomorphometric, and mechanical parameters. However, we recently demonstrated preserved bone mineral density (BMD) and mechanical strength of callus 6 weeks after fracture in experimental OP [9], in line with the findings by Kubo et al. [8] at the same time point. In support, Wheeler et al. [10] report no difference between OVX and sham rats in mechanical strength of callus at 4,6 , and 8 weeks after fracture. Also, recent data support unaltered fracture healing mechanisms during OP [11]. Thus, data are conflicting and, moreover, only a limited number of studies look into the molecular events involved in fracture repair in OP.

An additional predictor in the development of postmenopausal OP is vitamin D deficiency, which also may influence bone repair. Vitamin D deficiency is common among women with OP [12] and women with fractures regardless of age [13], leading to accelerated bone resorption. In support, OVX rats with vitamin D depletion develop site-specific bone loss similar to what is observed in women with postmenopausal OP [14]. Additionally, oral administration of $1,25(\mathrm{OH})_{2}$ vitamin $\mathrm{D}_{3}$ has recently been shown to improve fracture healing in OVX rats [15]. Interestingly, both estrogen [16] and vitamin D [17, 18] influence the expression and synthesis of ECM proteins, and such proteins play important roles in mediating cellular function and may serve as important modulators of bone regeneration.

Thus, we hypothesized that lack of estrogen and vitamin $D$ will influence global gene expression as well as the synthesis and ultrastructural distribution of ECM molecules in the fracture callus and, consequently, the capacity of fracture repair. To test this hypothesis, we examined global gene expression and in situ mRNA expression as well as the ultrastructural protein distribution of two major phosphoproteins in bone, i.e., osteopontin (OPN) and bone sialoprotein (BSP), and two osteoclast enzymes, i.e., tartrate-resistant acid phosphatase (TRAP) and cathepsin $\mathrm{K}$ (CTK), in the callus 3 and 6 weeks after tibial fracture of vitamin D-depleted OVX rats. Sham-operated, age-matched controls were used for comparison.

\section{Methods}

Animals and Tissue Preparation

All animal procedures were approved by the Norwegian Animal Research Authority. The experimental animal model was the same as previously presented [9]. In brief, 43 female Wistar rats (10 weeks of age with a mean body weight of $235 \mathrm{~g}$ [range 197-272]) were randomly assigned to two groups: OVX-D (ovariectomy followed by vitamin $\mathrm{D}_{3^{-}}$ deficient diet and 3 months' observation) and sham-treated (abdominal skin incision and normal diet in the same period of time). Bone loss was validated by dual-energy X-ray absorptiometry (DXA) in vivo before a closed fracture was made in the tibial midshaft and fixed with an intramedullary nail. For the fractured area, the value of the intramedullary nail was subtracted. Animals were killed at 3 and 6 weeks after fracture, and blood was collected before death. Animals for microarray analyses were killed by a phenobarbital overdose, and the dissected tibias were snap-frozen in liquid nitrogen. In the remaining animals, tissue was fixed by in vivo perfusion of $0.1 \mathrm{M}$ phosphate-buffered 2\% PFA during deep anesthesia, the tibias were dissected free from muscle and soft tissue, and the nail was carefully removed from a proximal port. Tibias were immersed in $2 \%$ PFA/0.5\% glutaraldehyde/0.1 $\mathrm{M}$ phosphate buffer and decalcified in $7 \%$ EDTA/0.5\% PFA. Bone samples for transmission electron microscopic (TEM) analyses were subjected to lowtemperature embedding in Lowicryl HM23 (Chemische Werke Lowi, Waldkraiburg, Germany) according to our established protocol [19]. Decalcified bone samples for histomorphometry and in situ hybridization (ISH) were embedded in paraffin according to a routine protocol.

\section{Histomorphometry}

Sagittal sections were cut from the paraffin-embedded decalcified callus samples, placed on glass slides, and stained with hematoxylin and eosin. To measure tissue composition of callus, digital micrographs $(\times 20)$ were sampled in a light microscope to cover the whole callus at one side of the medullary cavity. A virtual square grid $(50 \times 50 \mu \mathrm{m})$ was superimposed on the micrograph, and point counting was performed for bone, cartilage, and other connective/fibrous tissue. To compare osteoblast (Ob.S) and osteoclast (Oc.S) surfaces, five micrographs were sampled per callus section $(\times 40)$ and parallel lines $(50 \mu \mathrm{m}$ in between) were superimposed on each micrograph. Intersection counting was performed and Ob.S/Oc.S was calculated according to the standard histomorphometric procedure. For each animal, two sets of micrographs were sampled at two different tissue levels. The mean value was used to compare differences between groups.

RNA Isolation

Calluses were cut from the tibial diaphyses and homogenized in Trizol reagent (Invitrogen, Carlsbad, CA), and total RNA was isolated according to the manufacturer's 
protocol, as previously described [20]. RNA was further purified using the RNeasy micro kit (Qiagen, Valencia, CA). The concentration and quality of total RNA samples were assessed by spectrophotometry and the 2100 Bioanalyzer (Agilent Technologies, Santa Clara, CA).

\section{ISH}

Total RNA was reverse-transcribed to cDNA using the oligonucleotide primers listed in Table 1. cDNAs were cloned with the Dual Promoter TA Cloning Kit (Invitrogen) and sequenced (Seqlab, Göttingen, Germany). Digoxigenin (DIG)-conjugated complementary RNA (cRNA) probes were synthesized with a DIG-labeling kit (Roche Diagnostics, Oslo, Norway) using T7 or Sp6 RNA polymerase to yield probes in the sense or antisense orientation. For TRAP, cloning and DIG labeling were performed as previously described [21, 22]. Hybridization was performed by modification of a previously described protocol [23]. Briefly, dewaxed and proteinase K-digested sections of paraffin-embedded callus samples were postfixed in 4\% PFA. Following prehybridization (60 min, RT) in $50 \%$ formamide $/ 2 \times \mathrm{SSC}$, sections were hybridized (overnight, $42^{\circ} \mathrm{C}$ ) with $5 \mathrm{ng}$ probe in $50 \%$ formamide/ $2 \times$ $\mathrm{SSC} / 7.5 \%$ dextran sulfate. High-stringency washing was performed, and unbound probe was removed by RNAse treatment (Ambion, Austin, TX). Hybridized probes were detected using an alkaline phosphatase (AP)-conjugated sheep anti-DIG antibody followed by the AP substrate nitroblue tetrazolium chloride/5-bromo-4-chloro-3-indolylphosphate (Roche Diagnostics).

Immunohistochemistry and Immunogold Labeling

We cut 70-nm sections from Lowicryl HM23-embedded tissue and mounted them on formvar-coated nickel grids, and immunogold labeling was performed as previously described [19]. Briefly, after blocking with 5\% BSA in PBS, grid-mounted sections were incubated overnight with the primary polyclonal antibodies: anti-BSP (Chemicon, Temecula, CA), anti-TRAP (Immunodiagnostic Systems, Boldon, UK), anti-CTK (Santa Cruz Biotechnology, Santa Cruz, CA), and anti-OPN (raised in rabbits against a peptide sequence of the $\mathrm{N}$-terminal end of the molecule). Bound antibodies were visualized by 90 -min incubation

Table 1 Primer sequences for DIG-labeled cRNA probes

\begin{tabular}{lll}
\hline $\begin{array}{l}\text { Sequence } \\
\text { name }\end{array}$ & Sequence forward & Sequence reverse \\
\hline CTK & $5^{\prime}$-agacgcttacccgtatgtgg-3' & $5^{\prime}$-tggagagaagggaagcagag-3' \\
BSP & $5^{\prime}$-atggagatggcgatagttcg-3' & $5^{\prime}$-tgaaacccgttcagaaggac-3' \\
OPN & $5^{\prime}$-ctctgatcaggacagcaacg-3' & $5^{\prime}$-tcagggcccaaaacactatc-3' \\
\hline
\end{tabular}

with 10-nm colloidal gold conjugated with protein A. Nonspecific rabbit IgG was used as a negative control.

Analyses

\section{Microarray}

The analysis was performed essentially as previously described [20], except that biotin-labeled cRNA probes were hybridized to GeneChip ${ }^{\circledR}$ Rat Genome 2302.0 Array (Affymetrix, High Wycombe, UK). The quality of the RNA and cRNA probes was assessed by measuring the ratio between the $5^{\prime}$ and $3^{\prime}$ mRNAs for $\beta$-actin and GAPDH according to the Affymetrix-based test and found to be highly satisfactory.

\section{Light Microscopy and ISH}

Light microscopy was performed on paraffin-embedded callus specimens hybridized with DIG-labeled cRNA probes for OPN, BSP, TRAP and CTK. Seven to 10 digital images $(\times 20)$ were sampled per callus section. Point counting of mRNA-positive cells facing bone surfaces was performed using a semiautomatic image analyzer program (AnalySIS pro; Digital Soft Imaging System, Munster, Germany) with grid size of $25 \times 25 \mu \mathrm{m}$ [24]. In a parallel set of hematoxylin-stained sections, the corresponding callus area was identified and the total amount of osteoblasts and osteoclasts attached to bone surfaces counted $(\times 20)$. The ratio of mRNA-positive cells/total amount of bone surface cells was calculated for each set of corresponding images.

\section{TEM and Immunogold Analyses}

Micrographs were obtained by systematic random sampling of cells/surrounding matrix and analyzed using the semiautomatic interactive image analyzer software AnalySIS pro. All identified osteoclasts and at least four osteoblasts in one to three sections per animal were included in the analyses. An osteoclast was defined as a multinuclear cell attached to a matrix surface with characteristic membrane domains, i.e., ruffled border (RB) and/or clear zone (CZ), and an abundance of mitochondria in their cytoplasm [25]. An osteoblast was defined as a mononuclear cell attached to osteoid/bone matrix with a characteristic abundance of endoplasmic reticulum and Golgi complexes. A minimum of four images were sampled in each predetermined region according to our previous experience with protein distribution for BSP, OPN, TRAP, and CTK [26, 27]. Osteoid, mineralization fronts/cement lines, and woven bone matrix as well as osteoblasts and osteoclasts were identified at low magnification $(\times 2,500)$; and micrographs for gold particle measurements were sampled 
at high magnification $(\times 43,000)$. Gold particle density was calculated in the regions of interest (ROIs) according to the structural limits in the micrographs. Sections incubated with gold-labeled antibodies against BSP and OPN were analyzed with respect to both osteoblasts and osteoclasts, while only osteoclasts were studied in TRAP- and CTKlabeled sections. The results are based on the analysis of up to 42 and 24 osteoclasts at 3 and 6 weeks of healing, respectively. For osteoblasts, a minimum of 20 cells were analyzed in each group at 3 weeks and 12 at 6 weeks.

\section{Statistics}

Morphological results are given as means with standard deviation (SD) in parentheses. One-way analysis of variance (ANOVA) and multivariate analysis of variance (MANOVA) were used for light and electron microscopic data, respectively. For the latter, interest was focused on whether the overall distribution pattern for each of the four proteins differed between the groups. Thus, for a protein, only differences in overall comparison between the groups using MANOVA, and not differences in tests between subjects, were considered. $P<0.05$ was considered significant.

\section{Statistical Analysis of Gene Expression Profiling}

The 16 scanned chip images originating from the bone samples were processed using GCOS 1.4 (Affymetrix). The CEL files were imported into Array Assist software (v5.2.0; Iobion Informatics, La Jolla, CA) and normalized using the PLIER (probe logarithmic intensity error) algorithm in Array Assist to calculate relative signal values for each probe set. In order to filter for low signal values, the MAS5 algorithm in Array Assist was used to create a data set of absolute calls, showing the number of present and absent calls for each probe set. The filtration was performed by eliminating probe sets containing $\geq 13$ absent calls across the data set, resulting in a reduction of probe sets from 31,099 to 21,947. For expression comparisons of different groups, profiles were compared using a paired $t$-test. The results are expressed as fold changes (FCs), i.e., ratio of mean signals between compared groups. Gene lists were generated with the criteria of $P<0.05$ and $\mathrm{FC} \geq 2$.

\section{Results}

\section{Animal Model}

After randomization but prior to OVX and introduction of diet, the mean body weight was $4.7 \%$ lower in the OVX-D group compared to sham $(P=0.02)$. However, despite pair feeding, the OVX-D group gained more weight compared to sham-treated. The mean body weight was $8.6 \%$ and $12.9 \%$ higher in the OVX-D group after 3 and 6 weeks, respectively $(P<0.001)$.

All animals in the OVX-D group presented vitamin $\mathrm{D}_{3}$ and estrogen deficiency. $25(\mathrm{OH}) \mathrm{D} \leq 25 \mathrm{nmol} / \mathrm{l}$ in serum was considered as vitamin D deficiency, and all animals in the OVX-D group presented levels of $25(\mathrm{OH}) \mathrm{D} \leq 18 \mathrm{nmol} /$ 1, out of which $94.4 \%$ showed undetectable (i.e., $\leq 13 \mathrm{nmol} /$ 1) levels of 25(OH)D. Abolished ovarian function was defined as serum estradiol $<0.10 \mathrm{nmol} / \mathrm{l}$ (Hormone Laboratory, Aker University Hospital, Oslo, Norway). All OVXD animals presented serum estradiol levels below the reference values in complete loss of ovarian function (i.e., $\leq 0.08 \mathrm{nmol} / \mathrm{l})$.

Trabecular bone loss was confirmed by DXA showing decreased BMD in the vertebra and the femoral neck in OVX-D compared to sham-treated $(P<0.001)$ (Fig. 1a, data from [9]).

\section{Callus BMD}

DXA measurements showed no significant differences 2, 3, and 6 weeks after fracture (Fig. 1b, data from [9]).

\section{Callus Morphology and Histomorphometry}

Fracture calluses demonstrated intense osteogenesis after 3 weeks in both groups. However, there was large interindividual variation in size and ratio of intramembranous to endochondral bone formation; some calluses exhibited mainly cartilage/fibrous tissue in the space between the areas of subperiosteal bone formation, while others exhibited predominantly intramembranous bone formation beneath the periosteum adjacent to the fracture site (Fig. 2). Resorbing clasts were observed on both cartilaginous and osseous surfaces. At 6 weeks of healing, the same light microscopic heterogeneity was evident. However, a general tendency toward a decline in remodeling activity was observed.

Histomorphometry showed overall different callus composition in the OVX-D group after 3 weeks compared to sham $(P=0.02)$, with more woven bone and cartilage but less fibrous/connective tissues (Table 2). After 6 weeks, no overall difference was present. Furthermore, no differences between the groups were detected in Ob.S/ Oc.S at any time point (Table 3 ).

\section{Gene Profiling}

At 3 weeks of healing, 155 annotated genes and 88 expressed sequence tags (ESTs) were differently regulated in OVX-D vs. sham, out of which 35 genes were downregulated and 120 upregulated. At 6 weeks, 22 genes and eight ESTs were differently regulated, out of which six 

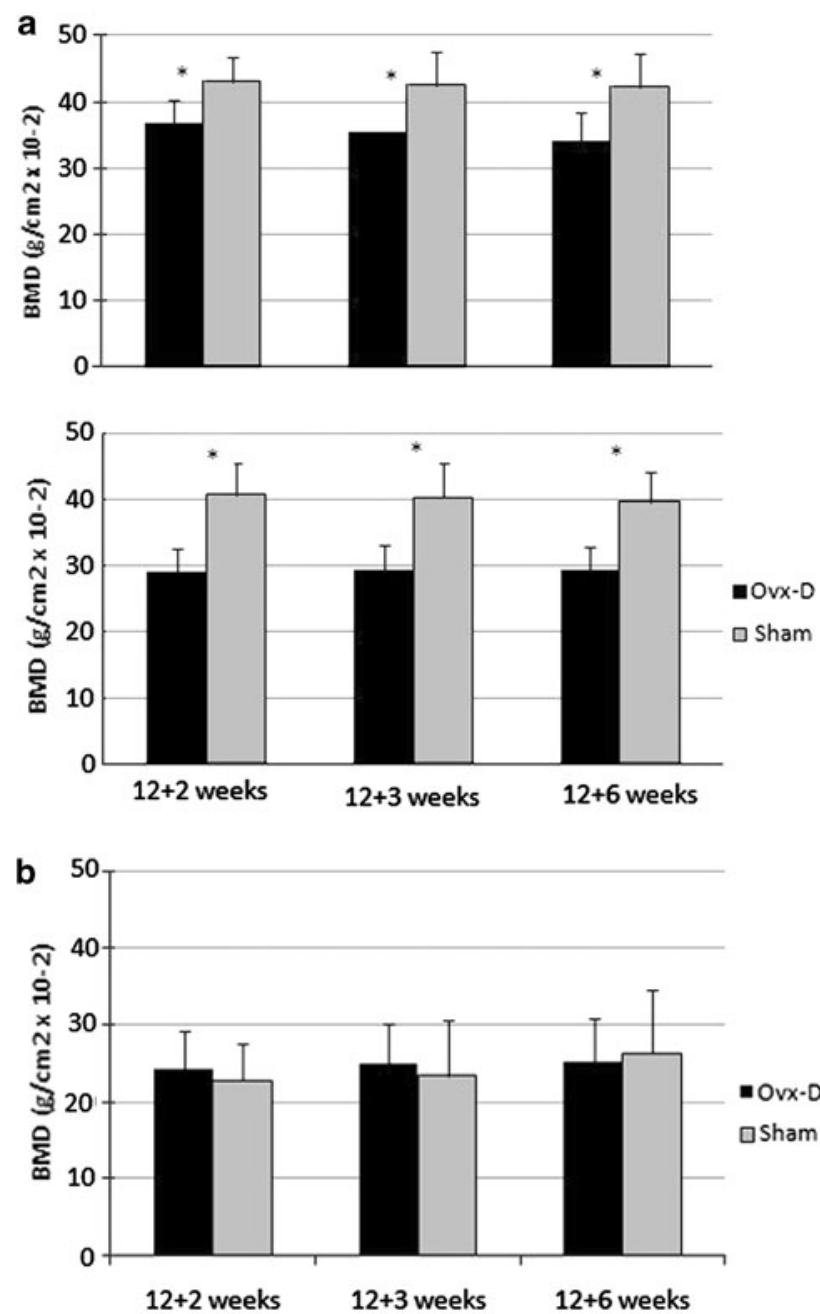

Fig. 1 DXA measurements of BMD in femoral neck (upper panel) and lumbar vertebrae (lower panel) (a) and fracture area (b) [9]. BMD in the femoral neck was significantly lower in OVX-D animals compared to sham at all measured time points $(* P<0.01)$. There were no significant differences between the right and left femoral neck. BMD in the fractured area did not differ significantly at any time points

genes were downregulated and 16 upregulated in OVX-D (Fig. 3; Supplementary Table S1). No significant differences in the mRNA levels for OPN, BSP, TRAP, or CTK between the groups or between the different time points were detected (Table 4). Among genes with suggested or known roles in bone metabolism, fibroblast growth factor 23 (FGF23) was downregulated $(P=0.02)$ and interleukin 17 (IL-17) receptor A was upregulated $(P=0.01)$ in the OP group at 3 weeks.

\section{Localization of OPN, BSP, TRAP, and CTK mRNA}

OPN and BSP mRNA were detected predominantly in osteoblastic cells and in some chondrocytes in the bonecartilage transitional zone but were undetectable in resorbing multinuclear cells. However, BSP mRNA expression in osteoclast progenitors cannot be excluded. CTK and TRAP mRNA were detected in multinucleated cells attached to bone/cartilage surfaces. In addition, several nonattached mononuclear cells, presumably osteoclast progenitors, were positive (Fig. 4).

\section{Ratios of mRNA-Expressing Cells on Bone Surfaces}

Compared to sham-treated animals, OVX-D animals exhibited an increased ratio of OPN mRNA-expressing cells at 3 weeks $(P=0.05)$ but a decreased ratio of BSP mRNAexpressing cells at 6 weeks $(P=0.01)$. Ratios for TRAP or CTK did not differ between the two groups. In the OVX-D group, ratios for BSP $(P=0.04)$, OPN $(P=0.01)$, and CTK $(P=0.04)$ decreased from 3 to 6 weeks. No differences between the time points were observed among these mRNAs for sham-treated animals (Table 5).

\section{Ultrastructural Protein Distribution}

The most intense accumulation of markers for both BSP and OPN was observed at electron-dense extracellular areas representing mineralization front/cement lines (Fig. 5) and, to a lesser extent, diffusely spread in the mineralized matrix of woven bone. BSP exhibited a characteristic pattern, with label being localized to discrete sites in the bone matrix corresponding to areas known to represent early mineral deposition [28] (Fig. 5b). Both BSP and OPN labeling showed a tendency toward increased intensity in the matrix facing the $\mathrm{CZ}$ of osteoclasts, the latter being most pronounced. No signal for BSP or OPN was found in the cartilaginous areas. Immunoreactivity for TRAP and CTK was consistently increased in the osteoclast cytoplasm and partly in the matrix facing the RB (Fig. 6). Lower levels were observed in the matrix facing the CZ. Intraluminal labeling of vessels was used as a measure of nonspecific binding/background and was low throughout the experiments, as was the nuclear labeling.

\section{Quantitative Immunogold Analysis}

No significant differences were found for the overall quantitative immunogold distribution of OPN and BSP, with respect to either groups or time points (Table 6).

CTK showed a different distribution with respect to osteoclasts between the groups after 3 weeks $(P=0.05)$, with generally increased labeling intensity in all compartments measured for osteoclasts in the OVX-D animals. Moreover, CTK labeling in the sham-treated animals differed from 3 to 6 weeks $(P=0.01)$. TRAP distribution did not differ between the groups or between different time points. Interestingly, TRAP labeling accumulated in the 
Fig. 2 Light micrographs of the fracture/callus area in the OVX$\mathrm{D}$ and sham groups at 3 and 6 weeks of healing. After 3 weeks OVX-D (a) and sham (b) appeared with bridging of callus gap and periosteal callus. After 6 weeks OVX-D (c) and sham (d) presented a more remodeled callus, although heterogeneity still was present. Paraffin-embedded section, $\mathrm{H} \& \mathrm{E}$ staining, $\times 4$ magnification
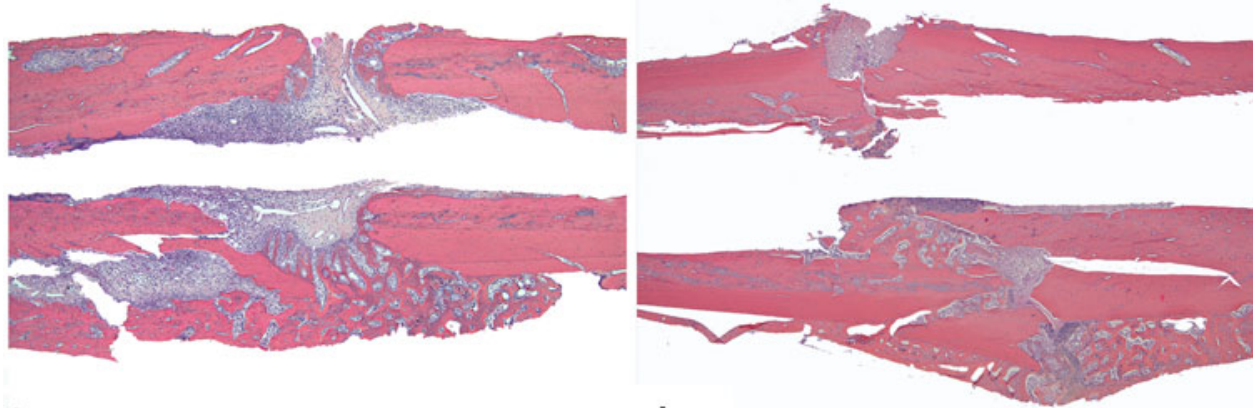

a

b
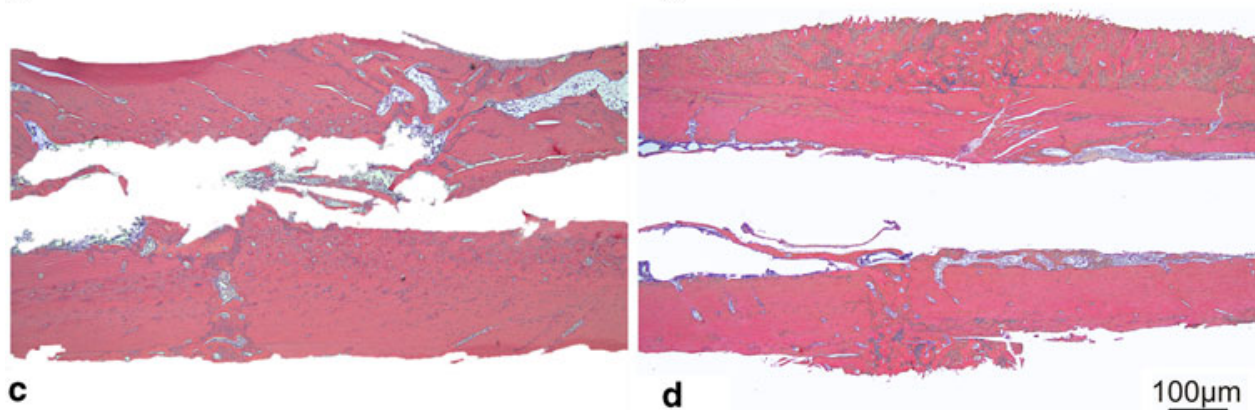

Table 2 Callus histomorphometry: callus composition

\begin{tabular}{llllll}
\hline Week & Group & $n$ & Woven bone & Cartilage & $\begin{array}{l}\text { Fibrous } \\
\text { connective tissue }\end{array}$ \\
\hline 3 & OVX-D* & 6 & $0.40 \pm 0.13$ & $0.34 \pm 0.054$ & $0.26 \pm 0.14$ \\
& Sham & 7 & $0.37 \pm 0.21$ & $0.29 \pm 0.12$ & $0.35 \pm 0.28$ \\
6 & OVX-D & 5 & $0.56 \pm 0.052$ & $0.24 \pm 0.089$ & $0.19 \pm 0.10$ \\
& Sham & 3 & $0.37 \pm 0.18$ & $0.34 \pm 0.16$ & $0.29 \pm 0.32$ \\
\hline
\end{tabular}

Values are mean $(\%) \pm \mathrm{SD}$. * Significantly different in overall composition compared to sham $(P=0.02)$

Table 3 Callus histomorphometry: cell types covering callus surfaces

\begin{tabular}{llllcl}
\hline Week & Group & $n$ & Ob.S & \multicolumn{1}{l}{ Oc.S } & $\begin{array}{l}\text { Other cells/ } \\
\text { eroded surface }\end{array}$ \\
\hline 3 & OVX-D & 6 & $0.78 \pm 0.029$ & $0.064 \pm 0.029$ & $0.16 \pm 0.044$ \\
& Sham & 7 & $0.72 \pm 0.060$ & $0.10 \pm 0.055$ & $0.18 \pm 0.08$ \\
6 & OVX-D & 5 & $0.72 \pm 0.080$ & $0.040 \pm 0.037$ & $0.24 \pm 0.071$ \\
& Sham & 3 & $0.53 \pm 0.17$ & $0.13 \pm 0.084$ & $0.34 \pm 0.11$ \\
\hline
\end{tabular}

Values are mean $(\%) \pm$ SD. Ob.S, osteoblast surface; Oc.S, osteoclast surface

matrix facing the $\mathrm{RB}$ of osteoclasts at 3 weeks in both groups but not at 6 weeks (Table 7).

\section{Discussion}

The present study addresses fracture healing in vitamin D-depleted OVX rats at the molecular level over a 6-week

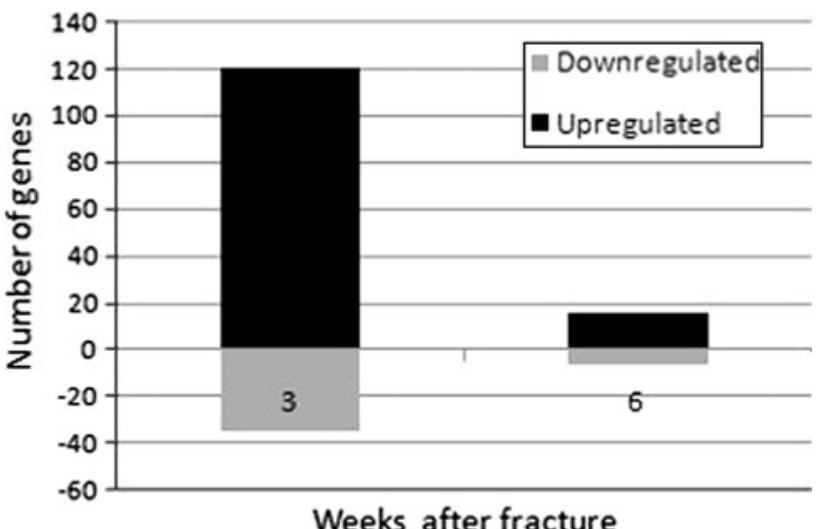

Fig. 3 Differentially expressed genes in the OVX-D group. DNA microarray analysis showed a larger number of annotated genes differently regulated in the OVX-D group compared to sham, the majority in an increased fashion and mostly after 3 weeks of healing. No genes encoding collagens or known matrix proteins were differentially regulated. Fold change $\geq 2, P \leq 0.05$

period. This is a well-established model, and in a recent study we observed bone loss in femoral neck and lumbal vertebrae but, somewhat surprisingly, little effect on the mechanical strength of healing fractures [9]. Estrogen and vitamin $\mathrm{D}$ exert their effects on bone in a spatial manner, which differs between metabolically active trabecular bone and weight-bearing cortical bone. Although vitamin D initially was reported to stimulate bone resorption in vitro [29], more recent in vivo findings indicate that active vitamin D analogues rather have an inhibitory effect on bone resorption, at least in a state of high turnover [30]. This inhibitory 
Table 4 Gene profiling of TRAP, OPN, BSP, and CTK

\begin{tabular}{llll}
\hline Gene ID & Gene name & Gene symbol & $\begin{array}{l}\text { FC } \\
\text { OVX-D vs. sham }\end{array}$ \\
\cline { 3 - 4 } & & & 3 weeks \\
\hline 1367942_at & Tartrate-resistant acid phosphatase 5 (TRAP) & Acp5 & 1.26 \\
1367581_a_at & Secreted phosphoprotein 1 (OPN) & Spp1 & 1.74 \\
1368416_at & Integrin binding sialoprotein (BSP) & Ibsp & 0.91 \\
1369947_at & Cathepsin K (CTK) & Ctsk & 1.22 \\
\hline
\end{tabular}

DNA microarray showed no differences between the OVX-D and sham groups in gene expression for the four bone remodeling markers TRAP, OPN, BSP, and CTK. FC (fold change) $\geq 2$

Fig. 4 OPN, BSP, TRAP, and CTK mRNA-positive cells in fracture callus at 3 weeks visualized by ISH. OPN mRNA (a) and BSP mRNA (c) positive osteoblasts, TRAP mRNA (b) and CTK mRNA (d) positive osteoclasts (arrows). WB, woven bone. $\mathrm{CB}$, cortical bone. Paraffin-embedded sections, $\times 20$ magnification
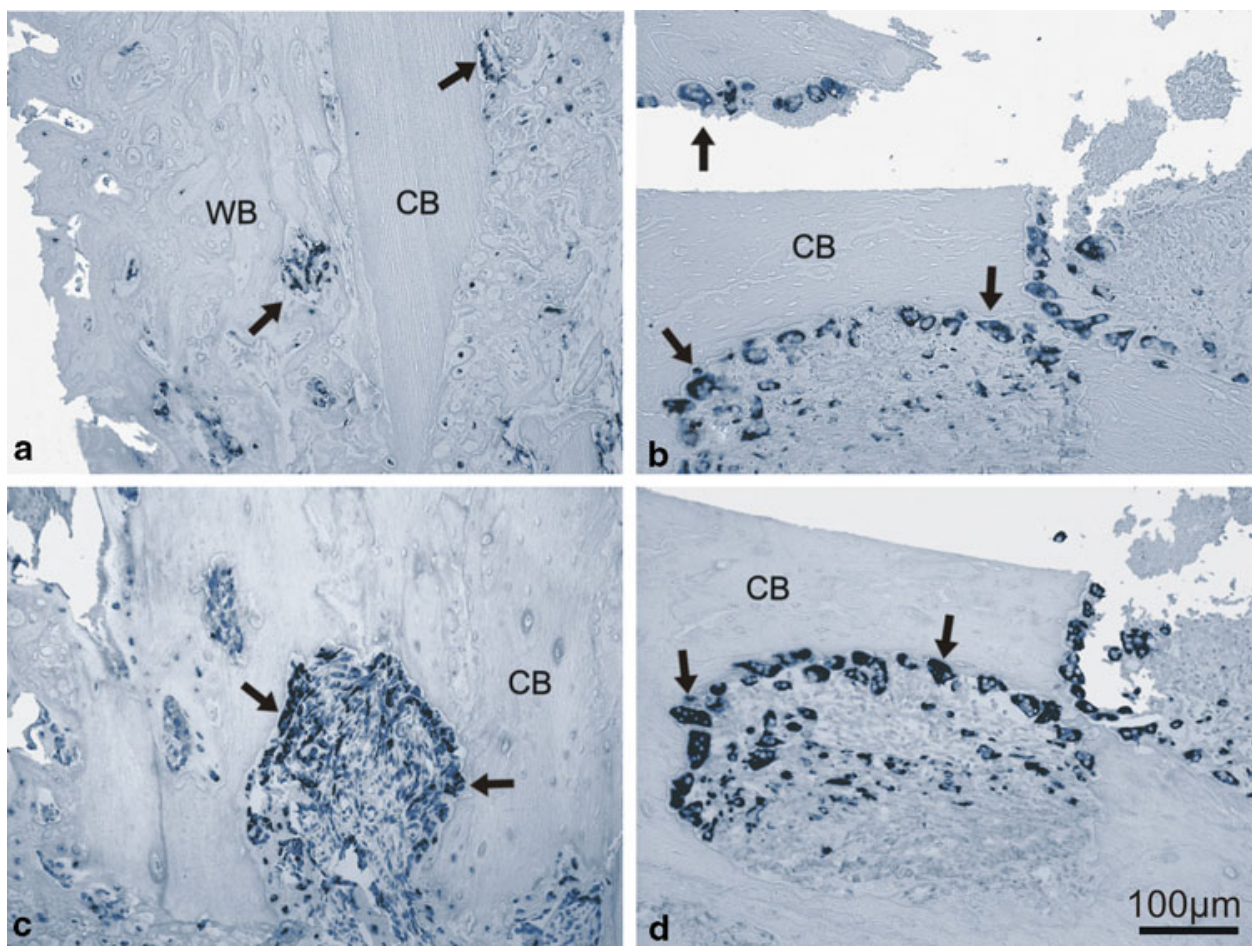

Table 5 Semiquantitative ISH for TRAP, CTK, OPN, and BSP

\begin{tabular}{llllc}
\hline mRNA & Group & $n$ & 3 weeks & 6 weeks \\
\hline TRAP & OVX-D & $6 / 5$ & $0.20 \pm 0.14$ & $0.068 \pm 0.053$ \\
& Sham & $7 / 4$ & $0.11 \pm 0.052$ & $0.18 \pm 0.14$ \\
CTK & OVX-D & $7 / 5$ & $0.17 \pm 0.095^{* *}$ & $0.059 \pm 0.032$ \\
& Sham & $7 / 4$ & $0.18 \pm 0.094$ & $0.14 \pm 0.14$ \\
OPN & OVX-D & $7 / 5$ & $0.33 \pm 0.15^{* * * *}$ & $0.12 \pm 0.047$ \\
& Sham & $7 / 4$ & $0.19 \pm 0.059$ & $0.12 \pm 0.085$ \\
BSP & OVX-D & $7 / 5$ & $0.21 \pm 0.14^{* *}$ & $0.022 \pm 0.034$ \\
& Sham & $7 / 4$ & $0.32 \pm 0.19$ & $0.18 \pm 0.089^{*}$
\end{tabular}

Results are mean $\pm \mathrm{SD}$. $n$, number of animals in the OVX-D and sham groups, respectively

* Significant difference between the groups $(P \leq 0.05)$; ** Significant difference between 3 and 6 weeks in the group $(P \leq 0.05)$ effect is reported to be less active in trabecular bone [31]. In a similar manner, estrogen deficiency following OVX results in bone loss at discrete sites in the skeleton, with most pronounced effect on trabecular bone [32].

Several genes associated with signal transduction, lipid and protein metabolism, ionic and protein transport, and neuropeptide and G-protein signaling were differently regulated in our OVX-D rat model. Many of these processes represent metabolic systems capable of maintaining bone homeostasis and tissue turnover. Most genes were expressed in an increased fashion in OVX-D compared to sham, in line with other reports on gene profiling of intact bone in OP [33]. Interestingly, no significant differences were detected among genes encoding noncollagenous proteins (NCPs) with known functions in bone metabolism. 


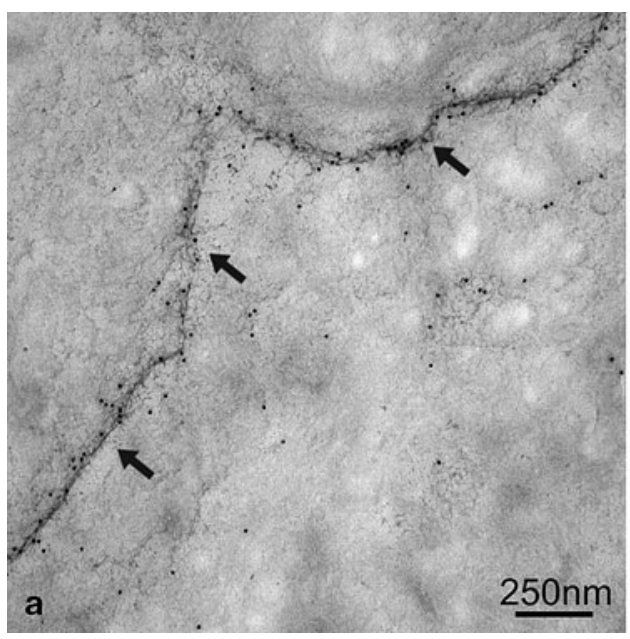

Fig. 5 Characteristic ultrastructural protein distribution of OPN and BSP. Micrographs of low-temperature embedded callus tissue after 3 weeks of healing incubated with gold-conjugated rabbit anti-rat antibodies against OPN and BSP. Immunogold signaling for OPN (a)

At 3 weeks, sevenfold more genes were differently regulated compared to 6 weeks; and consequently, changes in the healing pattern in OP would be expected in early stages. Among the differently regulated genes, the genes for IL-17 receptor A and FGF23 were up- and downregulated in OVX-D after 3 weeks. FGF23, a phosphaturic hormone and part of the newly discovered hormonal boneparathyroid-kidney axis, is modulated by $\mathrm{PTH}$, vitamin $\mathrm{D}$, and phosphate levels. The fact that $1,25(\mathrm{OH})_{2} \mathrm{D}_{3}$ upregulates FGF23 gene expression in bone [34] and undetectable serum levels of FGF23 are found in mice lacking the vitamin D receptor [35], downregulation of FGF23 in the OVX-D group could be explained by lack of dietary vitamin D. However, downregulation due to vitamin D deficiency would be expected to be present also after 6 weeks. Interestingly, FGF23 has recently been suggested as a putative marker of bone healing; decreased FGF23 mRNA expression is associated with delayed fracture healing in ovine bone [36]. Thus, downregulation of FGF23 in our model could also be associated with a possible delay in fracture healing at an early stage, although this is not supported by our other findings. IL-17 plays a role in bone loss in rheumatoid arthritis [37]. However, IL17RA null mice exhibit more pronounced bone loss compared to wildtype mice following OVX [38]; and thus, the role of this interleukin and its receptor seems diverse. Our observations call for further studies on the role of FGF23 and IL17RA during fracture healing in osteoporotic bone.

In our molecular studies we focused on four molecules with roles in tissue turnover taking place in the callus and, putatively, influenced by lack of estrogen and vitamin D depletion. For example, OPN is suggested to play roles both during osteoclast development/activity [39] and

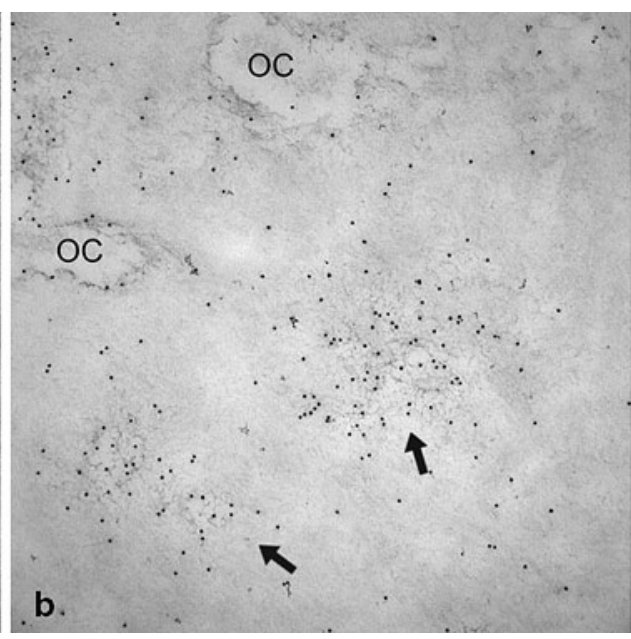

with distinct accumulation along a cement line (arrows) as previous described [52]. Intense BSP signaling (b) at early focus of mineralization, i.e., "mineralization noduli" (arrows). OC, osteocyte canaliculi. Lowicryl HM23-embedded, $\times 43,000$ magnification

during matrix mineralization [40]. Furthermore, OPN null mice are resistant to OVX-induced bone loss [41] and display disturbed fracture healing [42], suggesting a role for OPN during estrogen deficiency-related bone loss as well as in bone repair. Moreover, OPN is under the influence of both estrogen and vitamin D [16, 18].

mRNA expression for OPN, BSP, TRAP, and CTK in cell types was distributed as previously described in intact bone tissue [21, 26, 43]. OVX-D animals presented an increased ratio of OPN mRNA-expressing cells and a decreased ratio of BSP mRNA-expressing cells at 3 weeks and a significantly reduced ratio for BSP after 6 weeks of healing. These observations are in line with the reported inverse regulatory role of vitamin D for these proteins in vivo [44]. The observed increase in OPN and subsequent decline in BSP could possibly indicate suppressed osteoblastic differentiation in the OVX-D group.

In OVX-D rats at 3 weeks relative to 6 weeks, there was a significant decline in the ratio of cells expressing mRNA for OPN, BSP, and CTK but not that for TRAP. Thus, the decreased number of cells producing these bone turnover biomarkers in the OVX-D group at 6 vs. 3 weeks indicates a decline in synthetic activity/bone remodeling and a more remodeled callus. The latter supports the finding of Cao et al. [45] after 16 weeks of healing of a histologically more mature callus with preserved mechanical properties in OP vs. sham rats. Furthermore, these authors report no differences in healing after 6 weeks, in line with our results.

Quantitative immunoelectron microscopy showed only minor differences in labeling (Tables 5, 6, 7). The apparent inconsistency between our ISH and immunogold data is most likely due to the fact that the two data sets represent 
Fig. 6 Characteristic ultrastructural protein distribution of CTK and TRAP. Micrographs of low-temperature embedded callus tissue after 3 weeks of healing showing an active resorbing osteoclast attached to a bone surface (a) $(\times 1,900)$. Micrographs sampled at the ruffled border of the osteoclast in (a) at higher magnification $(\times 43,000)$, incubated with gold-conjugated rabbit anti-rat antibodies against CTK (b) and TRAP (c). Immunogold signaling for both CTK and TRAP showed accumulation in the osteoclast cytoplasm and in the ECM facing the ruffled border. Lowicryl HM23-embedded

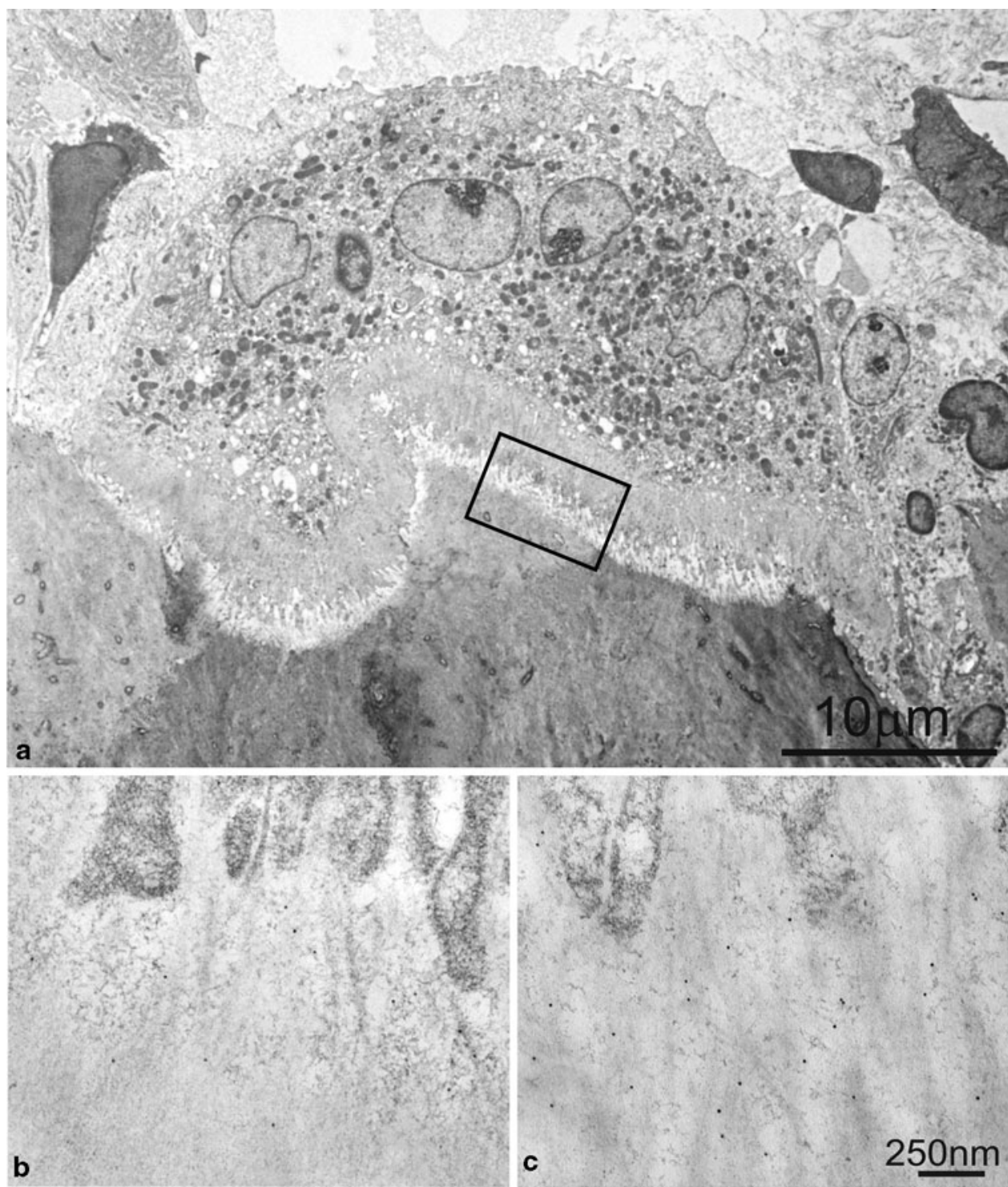

different aspects of callus turnover: while ISH data represent mRNA expression and thus protein synthesis, immunogold data reflect the present amount of protein in the tissue, which is the net result of synthesis, secretion, and degradation. That only minor differences of protein synthesis and tissue distribution were detected between the groups is supported by other studies [46, 47]. Interestingly, also recent studies of gross mechanisms in fracture healing in OVX rats [11] and transgenic mice [48] support our findings.

As with any animal model, there are limitations in simulating clinically relevant conditions. The calluses showed considerable heterogeneity both by macroscopic appearance and by histology, which was also reflected by large standard deviations in histomorphometric and BMD measurements. Except for a significant difference in tissue composition after 3 weeks, where the OP group presented calluses comprising more bone and cartilage and less fibrous tissue compared to sham, there was no systematic difference between the groups with respect to Ob.S/Oc.S, BMD, or histomorphometric parameters. Mechanical instability during fracture healing promotes cellular differentiation in the direction of endochondral bone formation [49], and variable degrees of fracture fixation in our experiment may explain the heterogeneity in the callus sample. It should be noted that since mechanical stress influences the mRNA expression in bone cells [50], this may have influenced our results by causing a relatively large variation among the samples. Furthermore, minimal-trauma fractures in OP patients are mostly localized to the proximal femur, vertebral column, and distal forearm [51], i.e., areas of high trabecular to cortical ratio. Thus, the present study concerns fracture healing in cortical bone, and it is possible that this type of bone healing is less influenced by estrogen and vitamin D deficiency. 


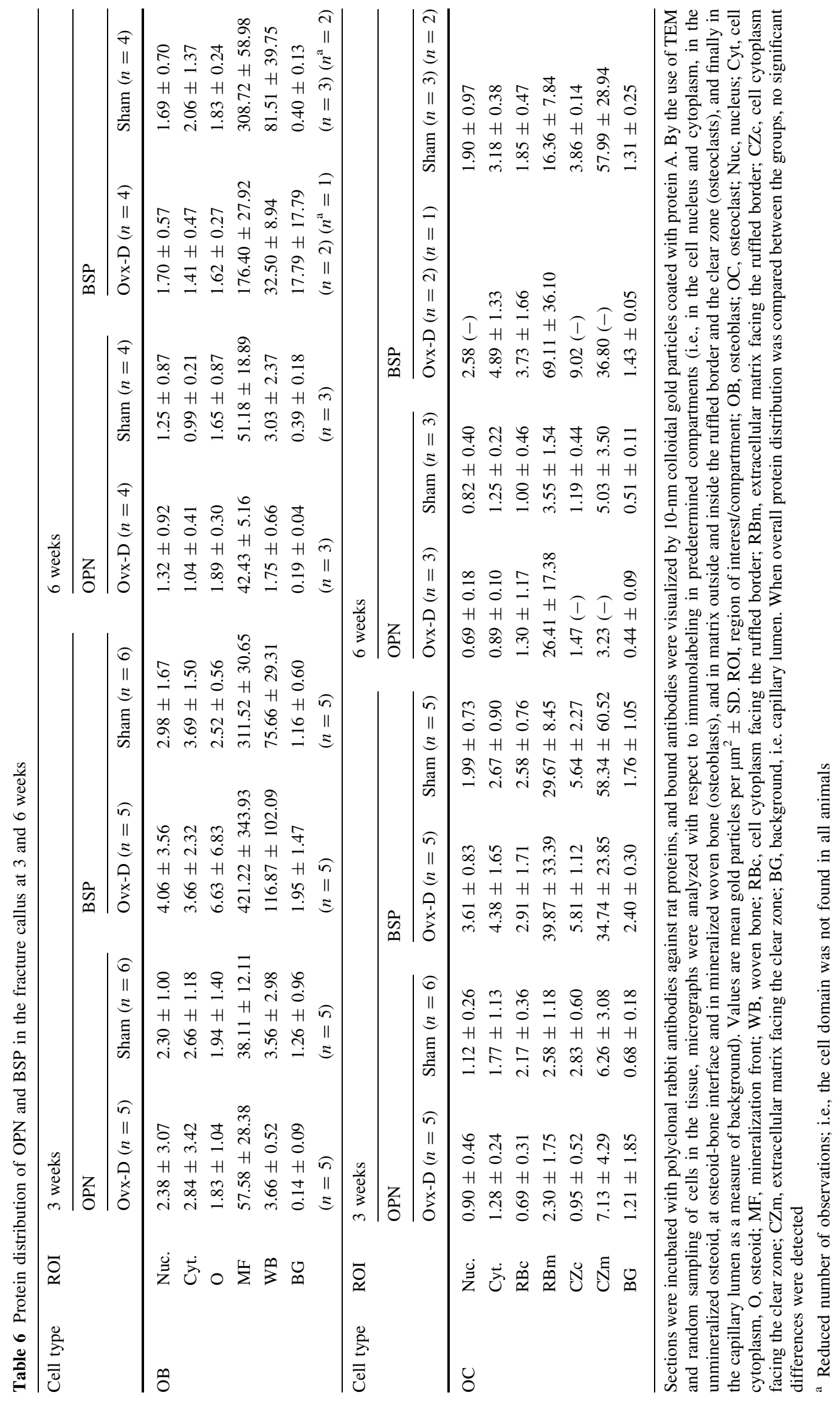




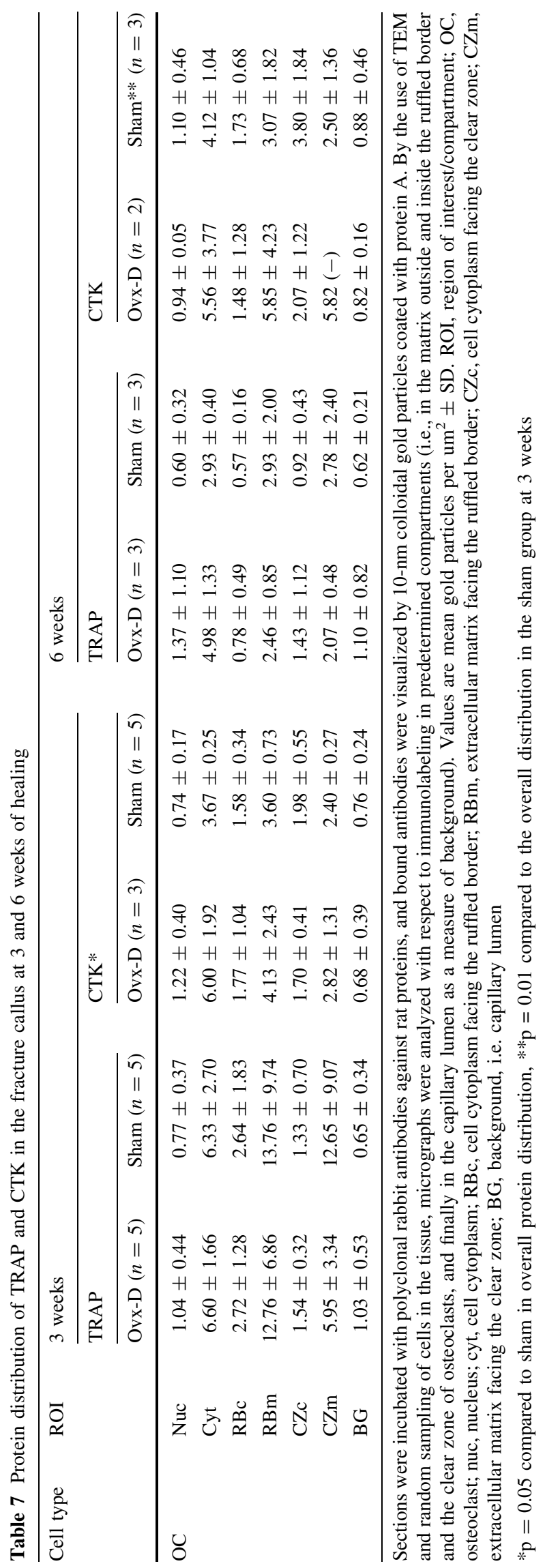


In summary, several genes are differently regulated in OP induced by OVX and vitamin D depletion, mostly in an early stage and the majority in an increased fashion, although no genes encoding NCPs with known function in bone metabolism were differently expressed. Against the background of only minor differences in the synthesis and protein expression of OPN, BSP, TRAP, and CTK in callus between OVX-D and sham-treated animals, our results suggest that the molecular composition of the fracture callus is not markedly skewed in OP.

Acknowledgements This work was financially supported by the EU (OSTEOGENE, FP6-502941), University of Oslo ("Småforsk"), and the Norwegian Association against Osteoporosis. Linda T. Dorg, Linda I. Solfjell, Aileen Murdoch-Larsen, and Maria Norgård are acknowledged for excellent technical support. Finally, Jan Erik Madsen and Sigbjorn Dimmen are acknowledged for help with animal surgery.

Open Access This article is distributed under the terms of the Creative Commons Attribution Noncommercial License which permits any noncommercial use, distribution, and reproduction in any medium, provided the original author(s) and source are credited.

\section{References}

1. Eastelle R (2006) Pathogenesis of postmenopausal osteoporosis. In: Favus M (ed) Primer on the metabolic bone diseases and disorders of mineral metabolism. American Society for Bone and Mineral Research, Washington, DC, pp 259-262

2. Recker R, Lappe J, Davies K, Heaney R (2000) Characterization of perimenopausal bone loss: a prospective study. J Bone Miner Res 15:1965-1973

3. Rodan GA (1991) Mechanical loading, estrogen deficiency, and the coupling of bone formation to bone resorption. J Bone Miner Res 6:527-530

4. Raisz LG (2005) Pathogenesis of osteoporosis: concepts, conflicts, and prospects. J Clin Invest 115:3318-3325

5. Nikolaou VS, Efstathopoulos N, Kontakis G, Kanakaris NK, Giannoudis PV (2009) The influence of osteoporosis in femoral fracture healing time. Injury 40:663-668

6. Thompson DD, Simmons HA, Pirie CM, Ke HZ (1995) FDA guidelines and animal models for osteoporosis. Bone 17:125S$133 \mathrm{~S}$

7. Namkung-Matthai H, Appleyard R, Jansen J, Hao Lin J, Maastricht S, Swain M, Mason RS, Murrell GA, Diwan AD, Diamond $T$ (2001) Osteoporosis influences the early period of fracture healing in a rat osteoporotic model. Bone 28:80-86

8. Kubo T, Shiga T, Hashimoto J, Yoshioka M, Honjo H, Urabe M, Kitajima I, Semba I, Hirasawa Y (1999) Osteoporosis influences the late period of fracture healing in a rat model prepared by ovariectomy and low calcium diet. J Steroid Biochem Mol Biol 68:197-202

9. Melhus G, Solberg LB, Dimmen S, Madsen JE, Nordsletten L, Reinholt FP (2007) Experimental osteoporosis induced by ovariectomy and vitamin D deficiency does not markedly affect fracture healing in rats. Acta Orthop 78:393-403

10. Wheeler DL, Eschbach EJ, Montfort MJ, Maheshwari P, McLoughlin SW (2000) Mechanical strength of fracture callus in osteopenic bone at different phases of healing. J Orthop Trauma 14:86-92

11. Shi HF, Cheung WH, Qin L, Leung AH, Leung KS (2009) Lowmagnitude high-frequency vibration treatment augments fracture healing in ovariectomy-induced osteoporotic bone. Bone. doi: 10.1016/j.bone.2009.11.028

12. Lips P, Hosking D, Lippuner K, Norquist JM, Wehren L, Maalouf G, Ragi-Eis S, Chandler J (2006) The prevalence of vitamin D inadequacy amongst women with osteoporosis: an international epidemiological investigation. J Intern Med 260:245-254

13. Steele B, Serota A, Helfet DL, Peterson M, Lyman S, Lane JM (2008) Vitamin D deficiency: a common occurrence in both highand low-energy fractures. HSS J 4:143-148

14. Kaastad TS, Reikeras O, Halvorsen V, Falch JA, Obrant KJ, Nordsletten L (2001) Vitamin D deficiency and ovariectomy reduced the strength of the femoral neck in rats. Calcif Tissue Int 69:102-108

15. Fu L, Tang T, Miao Y, Hao Y, Dai K (2009) Effect of 1,25dihydroxy vitamin $\mathrm{D}_{3}$ on fracture healing and bone remodeling in ovariectomized rat femora. Bone 44:893-898

16. Young MF IK, Kerr JM, Heegaard AM (1993) Molecular and cellular biology of the major noncollagenous proteins in bone. In: Noda M (ed) Molecular and cellular biology of bone. Academic Press, Orlando, pp 191-234

17. Oldberg A, Jirskog-Hed B, Axelsson S, Heinegard D (1989) Regulation of bone sialoprotein mRNA by steroid hormones. J Cell Biol 109:3183-3186

18. Yoon K, Buenaga R, Rodan GA (1987) Tissue specificity and developmental expression of rat osteopontin. Biochem Biophys Res Commun 148:1129-1136

19. Hultenby K, Reinholt FP, Oldberg A, Heinegard D (1991) Ultrastructural immunolocalization of osteopontin in metaphyseal and cortical bone. Matrix 11:206-213

20. Reppe S, Stilgren L, Olstad OK, Brixen K, Nissen-Meyer LS, Gautvik KM, Abrahamsen B (2006) Gene expression profiles give insight into the molecular pathology of bone in primary hyperparathyroidism. Bone 39:189-198

21. Ek-Rylander B, Bill P, Norgard M, Nilsson S, Andersson G (1991) Cloning, sequence, and developmental expression of a type 5, tartrate-resistant, acid phosphatase of rat bone. J Biol Chem 266:24684-24689

22. Lang P, Schultzberg M, Andersson G (2001) Expression and distribution of tartrate-resistant purple acid phosphatase in the rat nervous system. J Histochem Cytochem 49:379-396

23. Baekkevold ES, Yamanaka T, Palframan RT, Carlsen HS, Reinholt FP, von Andrian UH, Brandtzaeg P, Haraldsen G (2001) The CCR7 ligand elc (CCL19) is transcytosed in high endothelial venules and mediates T cell recruitment. J Exp Med 193:11051112

24. Gundersen HJ, Bendtsen TF, Korbo L, Marcussen N, Moller A, Nielsen K, Nyengaard JR, Pakkenberg B, Sorensen FB, Vesterby A et al (1988) Some new, simple and efficient stereological methods and their use in pathological research and diagnosis. Acta Pathol Microbiol Immunol Scand 96:379-394

25. Nordahl J, Andersson G, Reinholt FP (1998) Chondroclasts and osteoclasts in bones of young rats: comparison of ultrastructural and functional features. Calcif Tissue Int 63:401-408

26. Nordahl J, Hollberg K, Mengarelli-Widholm S, Andersson G, Reinholt FP (2000) Morphological and functional features of clasts in low phosphate, vitamin D-deficiency rickets. Calcif Tissue Int 67:400-407

27. Hollberg K, Nordahl J, Hultenby K, Mengarelli-Widholm S, Andersson G, Reinholt FP (2005) Polarization and secretion of cathepsin $\mathrm{K}$ precede tartrate-resistant acid phosphatase secretion to the ruffled border area during the activation of matrixresorbing clasts. J Bone Miner Metab 23:441-449 
28. Bianco P, Riminucci M, Silvestrini G, Bonucci E, Termine JD, Fisher LW, Robey PG (1993) Localization of bone sialoprotein (BSP) to Golgi and post-Golgi secretory structures in osteoblasts and to discrete sites in early bone matrix. J Histochem Cytochem 41:193-203

29. Raisz LG, Trummel CL, Holick MF, DeLuca HF (1972) 1,25Dihydroxycholecalciferol: a potent stimulator of bone resorption in tissue culture. Science 175:768-769

30. Shiraishi A, Takeda S, Masaki T, Higuchi Y, Uchiyama Y, Kubodera N, Sato K, Ikeda K, Nakamura T, Matsumoto T, Ogata E (2000) Alfacalcidol inhibits bone resorption and stimulates formation in an ovariectomized rat model of osteoporosis: distinct actions from estrogen. J Bone Miner Res 15:770-779

31. Baldock PA, Thomas GP, Hodge JM, Baker SU, Dressel U, O'Loughlin PD, Nicholson GC, Briffa KH, Eisman JA, Gardiner EM (2006) Vitamin D action and regulation of bone remodeling: suppression of osteoclastogenesis by the mature osteoblast. J Bone Miner Res 21:1618-1626

32. Baldock PA, Need AG, Moore RJ, Durbridge TC, Morris HA (1999) Discordance between bone turnover and bone loss: effects of aging and ovariectomy in the rat. J Bone Miner Res 14:14421448

33. Xiao Y, Fu H, Prasadam I, Yang YC, Hollinger JO (2007) Gene expression profiling of bone marrow stromal cells from juvenile, adult, aged and osteoporotic rats: with an emphasis on osteoporosis. Bone 40:700-715

34. Kolek OI, Hines ER, Jones MD, LeSueur LK, Lipko MA, Kiela PR, Collins JF, Haussler MR, Ghishan FK (2005) 1alpha,25-Dihydroxyvitamin $\mathrm{D}_{3}$ upregulates FGF23 gene expression in bone: the final link in a renal-gastrointestinal-skeletal axis that controls phosphate transport. Am J Physiol Gastrointest Liver Physiol 289:G1036-G1042

35. Yu X, Sabbagh Y, Davis SI, Demay MB, White KE (2005) Genetic dissection of phosphate- and vitamin D-mediated regulation of circulating Fgf23 concentrations. Bone 36:971-977

36. Goebel S, Lienau J, Rammoser U, Seefried L, Wintgens KF, Seufert J, Duda G, Jakob F, Ebert R (2009) FGF23 is a putative marker for bone healing and regeneration. J Orthop Res 27:11411146

37. Yu JJ, Ruddy MJ, Conti HR, Boonanantanasarn K, Gaffen SL (2008) The interleukin-17 receptor plays a gender-dependent role in host protection against Porphyromonas gingivalis-induced periodontal bone loss. Infect Immun 76:4206-4213

38. Goswami J, Hernandez-Santos N, Zuniga LA, Gaffen SL (2009) A bone-protective role for IL-17 receptor signaling in ovariectomy-induced bone loss. Eur J Immunol 39:2831-2839

39. Franzen A, Hultenby K, Reinholt FP, Onnerfjord P, Heinegard D (2008) Altered osteoclast development and function in osteopontin deficient mice. J Orthop Res 26:721-728
40. Boskey AL, Maresca M, Ullrich W, Doty SB, Butler WT, Prince CW (1993) Osteopontin-hydroxyapatite interactions in vitro: inhibition of hydroxyapatite formation and growth in a gelatingel. Bone Miner 22:147-159

41. Yoshitake H, Rittling SR, Denhardt DT, Noda M (1999) Osteopontin-deficient mice are resistant to ovariectomy-induced bone resorption. Proc Natl Acad Sci USA 96:8156-8160

42. Duvall CL, Taylor WR, Weiss D, Wojtowicz AM, Guldberg RE (2007) Impaired angiogenesis, early callus formation, and late stage remodeling in fracture healing of osteopontin-deficient mice. J Bone Miner Res 22:286-297

43. Hultenby K, Reinholt FP, Norgard M, Oldberg A, Wendel M, Heinegard D (1994) Distribution and synthesis of bone sialoprotein in metaphyseal bone of young rats show a distinctly different pattern from that of osteopontin. Eur J Cell Biol 63:230-239

44. Chen JJ, Jin H, Ranly DM, Sodek J, Boyan BD (1999) Altered expression of bone sialoproteins in vitamin D-deficient rBSP2.7Luc transgenic mice. J Bone Miner Res 14:221-229

45. Cao Y, Mori S, Mashiba T, Westmore MS, Ma L, Sato M, Akiyama $T$, Shi L, Komatsubara S, Miyamoto $K$, Norimatsu $H$ (2002) Raloxifene, estrogen, and alendronate affect the processes of fracture repair differently in ovariectomized rats. J Bone Miner Res 17:2237-2246

46. Jeong KS, Lee J, Jeong W, Noh DH, Do SH, Kim YK (2005) Measurement of estrogen effect on bone turnover by $2 \mathrm{H}_{2} \mathrm{O}$ labeling. Calcif Tissue Int 76:365-370

47. Huang J, Wang X, Zhang TL, Wang K (2009) Alterations of ovariectomized rat bone and impact of non-collagenous proteins on mineralization. Joint Bone Spine 76:176-183

48. Egermann M, Heil P, Tami A, Ito K, Janicki P, Von Rechenberg B, Hofstetter W, Richards PJ (2009) Influence of defective bone marrow osteogenesis on fracture repair in an experimental model of senile osteoporosis. J Orthop Res. doi:10.1002/jor.21041

49. Gerstenfeld LC, Cullinane DM, Barnes GL, Graves DT, Einhorn TA (2003) Fracture healing as a post-natal developmental process: molecular, spatial, and temporal aspects of its regulation. $\mathbf{J}$ Cell Biochem 88:873-884

50. Palomares KT, Gleason RE, Mason ZD, Cullinane DM, Einhorn TA, Gerstenfeld LC, Morgan EF (2009) Mechanical stimulation alters tissue differentiation and molecular expression during bone healing. J Orthop Res 27:1123-1132

51. Harvey NES, Cooper C (2006) Epidemiology of osteoporotic fractures. In: Favus MJ (ed) Primer on the metabolic bone diseases and disorders of mineral metabolism. American Society for Bone and Mineral Research, Washington, DC, pp 244-248

52. McKee MD, Nanci A (1996) Osteopontin at mineralized tissue interfaces in bone, teeth, and osseointegrated implants: ultrastructural distribution and implications for mineralized tissue formation, turnover, and repair. Microsc Res Tech 33:141-164 